Revue

d'ethnoécologie

\section{Revue d'ethnoécologie}

12 | 2017

La Poule. Pratiques d'élevage et histoire culturelle

\title{
Pullus, gallus et gallina : déclinaisons antiques
}

Representations of pullus, gallus and gallina in the Graeco-Roman world

\author{
Nicole Blanc
}

\section{(2) OpenEdition}

Journals

Édition électronique

URL : http://journals.openedition.org/ethnoecologie/3264

DOI : 10.4000/ethnoecologie.3264

ISSN : 2267-2419

Éditeur

Laboratoire Eco-anthropologie et Ethnobiologie

Référence électronique

Nicole Blanc, "Pullus, gallus et gallina : déclinaisons antiques », Revue d'ethnoécologie [En ligne], 12 | 2017, mis en ligne le 18 décembre 2017, consulté le 20 avril 2019. URL : http:// journals.openedition.org/ethnoecologie/3264 ; DOI : 10.4000/ethnoecologie.3264

Ce document a été généré automatiquement le 20 avril 2019

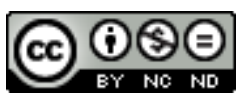

Revue d'ethnoécologie est mis à disposition selon les termes de la licence Creative Commons Attribution - Pas d'Utilisation Commerciale - Pas de Modification 4.0 International. 


\title{
Pullus, gallus et gallina: déclinaisons antiques
}

\author{
Representations of pullus, gallus and gallina in the Graeco-Roman world
}

\author{
Nicole Blanc
}

1 Dans l'Antiquité gréco-romaine, la poule n'est pas le membre le plus visible ni le plus éminent de l'ordre des gallinacés. Produit d'élevage et de consommation, elle interroge les pratiques agronomiques et culinaires; son petit, le jeune poulet, participe de la vie religieuse et politique; le coq, par sa beauté et son caractère belliqueux, domine l'imaginaire et les représentations ${ }^{1}$. Si le naturaliste Pline l'Ancien les classe bien tous les trois dans la même famille, les représentations écrites et figurées distinguent des entités différentes dont cette brève évocation brossera à grands traits le contour.

\section{Gallus, le guerrier vainqueur}

2 Au commencement était le coq qui se distingue par sa fierté et son orgueil, approche anthropomorphique encore d'actualité. Pline le classe au deuxième rang, après le paon, comme animal « sensible à la gloire » :

«Il marche la tête haute, la crête droite ; [...] seuls parmi les oiseaux, ils [les coqs] regardent souvent le ciel, dressant aussi dans les airs leur queue recourbée comme une faucille. Aussi inspirent-ils de la terreur, même aux lions, les plus courageux des animaux » (Naturalis Historia [NH], X, 48).

3 Car cette fierté, à la différence de celle du paon, va de pair avec une ardeur guerrière qui fascine dans une civilisation où l'apprentissage du combat est la base de l'éducation virile.

4 Cet aspect de l'animal est très largement illustré dans la céramique grecque où le couple de coqs affrontés ne constitue pas qu'un motif héraldique : les scènes de combat, figurées dès la fin $d u v^{e}$ siècle av. J.-C., reflètent une réalité dont les artisans antiques rendent avec bonheur et plus ou moins de talent tous les détails (Bruneau 1965, Hoffmann 1974). Ce sont d'abord les enfants et les adolescents qui se passionnent pour ce jeu. Ganymède, l'éphèbe par excellence, est couramment figuré avec ses deux attributs: le cerceau, 
exercice classique de la palestre, et le coq, présent traditionnel à Athènes de l'amant, ici Zeus, au jeune homme aimé (Hoffmann 1974 : 206-209, fig. 12-13) (Figure 1). Platon, dans les Lois (VII, 789b), fait dire à l'Athénien : "Chez nous, non seulement des garçons mais même des adultes élèvent de jeunes oiseaux pour les faire combattre les uns contre les autres ». Dans les Euménides d'Eschyle (861-863), Athéna s'adresse au chœur en ces termes: "Ne va pas, comme on excite l'humeur des coqs, installer parmi mes citoyens une guerre intestine où l'on est brave les uns contre les autres». Plus prosaïquement, Xénophon livre dans Le Banquet (IV, 9), les astuces des propriétaires : « Il est bon que celui qui s'en va au banquet mange de l'oignon, comme certaines personnes donnent de l'ail à leurs coqs avant de les mettre aux prises ». C'est la face moins noble, plus populaire et mercantile de ces combats qui pouvaient se dérouler dans les tavernes où les joueurs avaient leurs habitudes. C'est ainsi qu'Eschine disqualifie son adversaire politique Timarque : «Il passait ses journées au tripot; là se dresse l'estrade, on met les coqs aux prises et on joue aux dés " (Contre Timarque, 53). À la même époque toutefois, le thème peut revêtir une signification plus profonde, en endossant les grands mythes de l'épopée nationale. Le rhéteur grec Élien (175-235 ap. J.-C.) rapporte qu'après leur victoire sur les Perses, les Athéniens prescrivirent par une loi que des combats de coqs publics eussent lieu un jour par an au théâtre ; et il explique ainsi l'origine de cette loi :

"Thémistocle, conduisant les forces armées de la cité contre les Barbares, aperçut deux coqs qui se battaient avec beaucoup d'ardeur. Il arrêta son armée et dit à ses hommes : "Ceux-ci ne peinent pas pour la défense de leur patrie, ni de leurs dieux nationaux, ni des tombeaux de leurs ancêtres, ni pour la gloire, ni pour la liberté, ni pour leurs enfants, mais pour n'être pas le vaincu et ne pas céder à l'adversaire." Par ces paroles, Thémistocle affermit le courage des Athéniens » (Histoires Var., II, 28).

L'anecdote est apocryphe mais le propos, placé dans la bouche du vainqueur de Salamine, montre que l'ardeur guerrière du coq peut signifier le courage, vertu civique première lorsqu'Athènes est menacée par les Perses. On en verra la confirmation dans l'iconographie des vases panathénaïques, les amphores remises en prix aux vainqueurs lors des Grandes Panathénées, fêtes solennelles célébrées à Athènes en l'honneur de la divinité protectrice de la cité. Ces grands vases portent toujours sur une face la déesse Athéna, figurée entre deux coqs, symbolisant la lutte et la victoire (Lissarague 2013 : fig. 3) (Figure 2). Le succès des compétitions sportives dans le monde grec tient à leur signification civique et religieuse : l'athlète est un citoyen entraîné à défendre sa patrie. Le combat de coqs peut donc revêtir la dimension d'une compétition sportive (Dumont 1988). 
Figure 1 : Ganymède. Cratère en cloche à figures rouges du Peintre de Berlin, vers 490-480 av. J.-C.

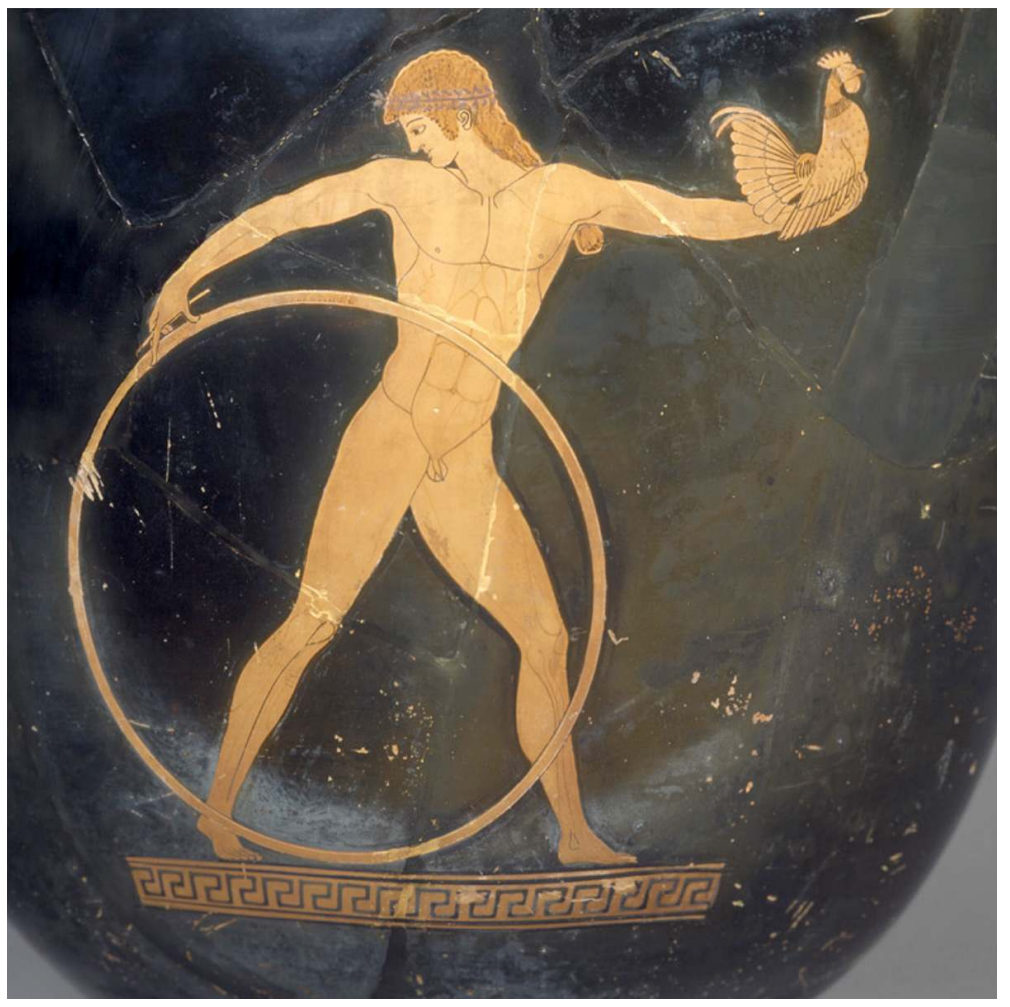

(c) Musée du Louvre 
Figure 2 : Athéna entre deux coqs. Amphore de type panathénaïque. De Vulci. Londres, British Museum. Vers 530 av. J.-C.

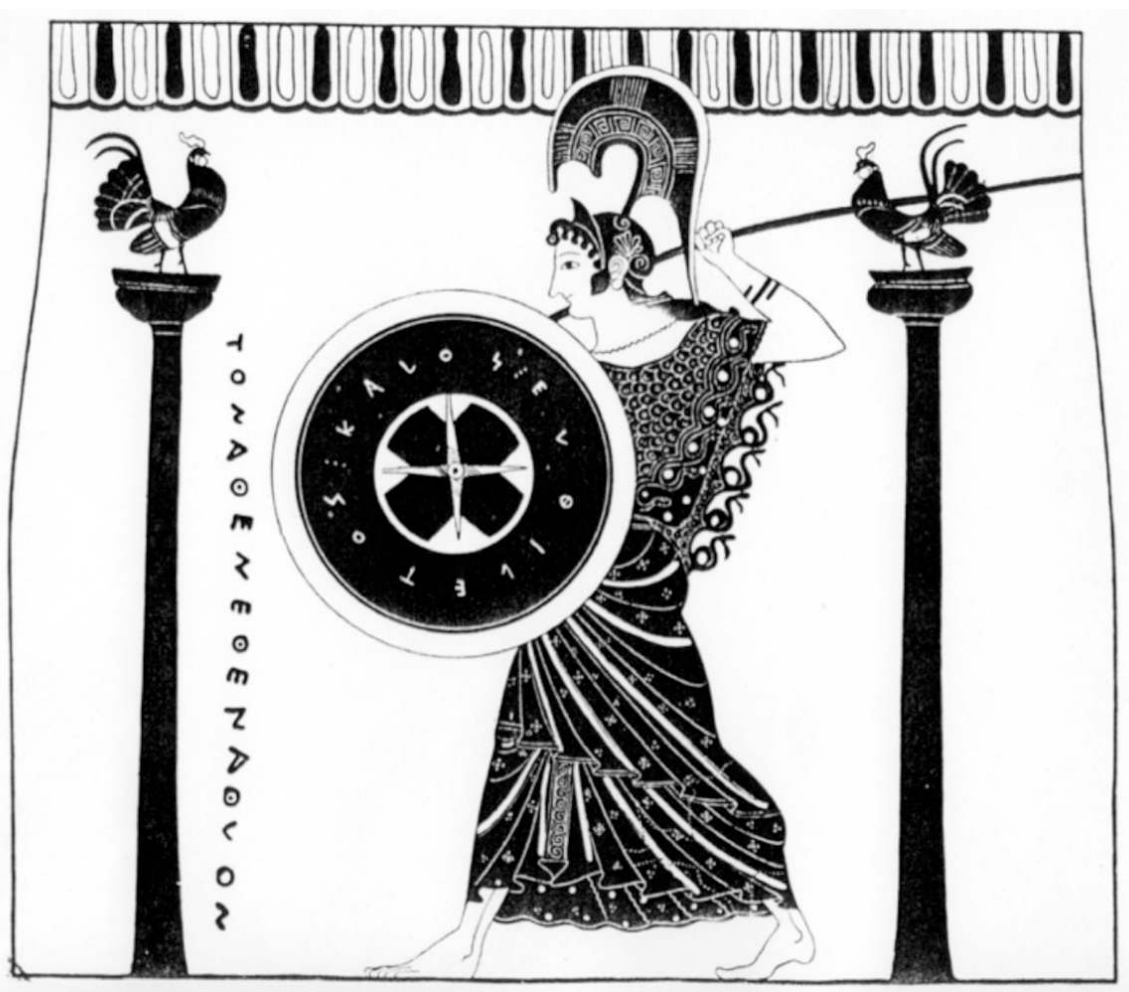

D’après Lissarague 2013

6 Les élites romaines, avec les conquêtes, assimilent en les adaptant les valeurs du monde grec et ses représentations : c'est à ce titre que le motif appartient au répertoire des mosaïques et peintures murales du décor domestique. C'est pourquoi souvent la compétition se déroule symboliquement dans le cadre de la palestre. À Pompéi, dans la riche maison du Labyrinthe, un emblema polychrome, daté de la fin du $\mathrm{II}^{\mathrm{e}}$ siècle av. J.-C., affiche, dans le secteur de réception, la culture hellénistique du propriétaire (Figure 3). Un portique figuré par deux colonnes plante le décor ; deux coqs s'affrontent au premier plan; le vainqueur se dresse fièrement, tandis que son adversaire, perdant son sang, baisse la tête; son maître à droite indique sa défaite et son affliction par le geste traditionnel du deuil. Derrière le coq vainqueur, le propriétaire s'élance avec la couronne de la victoire, qu'il va consacrer à l'Hermès de la palestre, la statue qui domine sur un socle au second plan; un troisième personnage, plus petit, un jeune esclave sans doute, brandit une immense palme qui se dresse au centre, symbole explicite de la victoire (Strocka 1991 : 48-49, 99-100, fig. 322 ; Tammisto 1997 : 346-347, cat. LS3, pl. V, fig. LS3, 1). Deux siècles plus tard, les Vettii, de riches affranchis, ont choisi de faire figurer trois fois un combat de coqs dans le secteur de l'atrium, cœur et pars publica de leur domus (Pompei, Pitture e Mosaici [PPM], V : 470-471, fig. 1 ; 495, fig. 43 ; 497, fig. 46). La scène peut être traitée sur un mode parodique : c'est un nain qui offre la palme au coq vainqueur plus grand que lui sur une peinture campanienne au Musée de Naples (Tamisto 1997 : 30, pl. V fig. LS3, 2). Le succès du motif est attesté par sa transmission continue, selon un schéma presque inchangé jusqu'à la fin de l'Antiquité (Bruneau 1965 : 110-120). 
Figure 3 : Combat de coqs. Mosaïque, Pompéi, maison du Labyrinthe, $\|^{\mathrm{e}} \mathrm{s}$. av. J.-C.

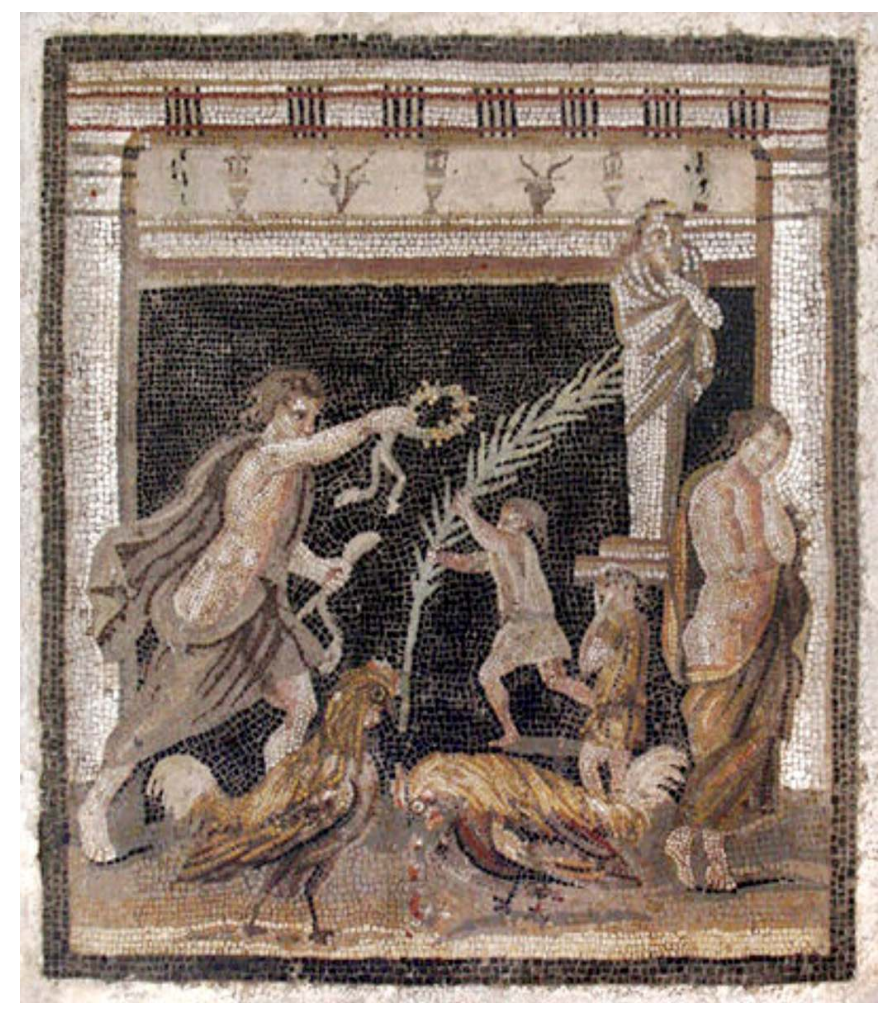

D’après Strocka 1991

\section{Messager des dieux}

7 Si Pline moque l'« athlète emplumé ", il vante à l'inverse ces vigiles nocturni qui, tels les vigiles urbains, sont les gardiens et la police de l'Urbs. Leur aptitude à marquer le temps leur donne en effet une place et une autorité singulières dans l'ordre de la création.

«La nature les a créés pour remettre les hommes au travail et les arracher au sommeil. Ils connaissent les constellations [...]. Ils vont se coucher avec le soleil et à la quatrième veille militaire, ils nous rappellent aux occupations et au travail. Ils ne souffrent pas que le lever du soleil nous surprenne : ils annoncent par leur chant la venue du jour et ce chant lui-même en battant des ailes » $(\mathrm{NH}, \mathrm{X}, 40)$.

On a du mal aujourd'hui à mesurer ce que pouvait avoir de proprement surnaturelle cette vertu horlogère. Ils connaissent les constellations, dit Pline, ce qui en fait les garants de l'ordre cosmique. Or, la science du mouvement des astres est d'abord l'apanage des savants et des philosophes. Sur la célèbre mosaïque de Pompéi qui donne à voir une représentation idéale de l'Académie de Platon (Rashed 2012), les philosophes raisonnent autour d'une sphère armillaire placée au premier plan, caractérisée par les bandes croisées marquant la trajectoire des planètes ${ }^{2}$. Derrière eux, au centre de la scène, se dresse une méridienne, image tangible du mouvement des planètes et du système solaire. Cette proximité des astres et des sphères divines explique leur rôle de messager des dieux. Les oies du Capitole sont célèbres, mais on connaît moins les coqs de Thèbes, liés aussi à un prodige célèbre. En chantant toute la nuit, ils avaient annoncé la victoire des Thébains à Leuctres parce que, avaient dit les devins béotiens, ces oiseaux ont coutume de se taire quand ils sont vaincus et de chanter quand ils triomphent (Cicéron, Div., II, 56-57). 
9 Au-delà de ces prodiges circonstanciels, les gallinacés ont joué un rôle officiel dans la religion romaine, dans une forme de pratique divinatoire héritée de la religion étrusque : la prise des auspices au moyen des poulets sacrés, le tripudium ${ }^{3}$. Le terme désigne littéralement le présage donné par un objet tombant à terre, en l'occurrence la nourriture tombant du bec des poulets (Cicéron, Div., I, 27-28). Le rituel consistait en effet à observer la prise de nourriture des volatiles, apportés dans des cages au magistrat qui présidait la cérémonie: s'ils mangeaient avec avidité, les auspices étaient favorables, dans le cas contraire, les auspices étaient défavorables. Sur un autel des Lares daté de 2 av. J.-C., provenant du vicus sandalarius, le quartier des sandales à Florence, les deux ministres du culte entourent Auguste, tête voilée, tenant le lituus, insigne de sa charge d'augure; un poulet picore à ses pieds, évoquant le rituel du tripudium (Turcan 1995: 86, fig. 101) (Figure 4). Ce mode de divination entraînait plus que tout autre la suspicion, car les pullarii, assistants du culte chargés de l'entretien des poulets, pouvaient l'orienter aisément dans le sens désiré en faisant jeûner les animaux à l'avance et en leur distribuant des boulettes trop grosses pour être absorbées d'un seul coup. Durant la guerre contre les Samnites, en 293 av. J.-C., une tentative de fraude fut déjouée par des cavaliers qui avaient entendu les pullarii en discuter entre eux (Tite Live, X, 40). Cicéron qui est plus que critique à l'égard de ce mode de divination lié aux débuts de la République (Guillaumont 2006 302-317) affirme qu'il n'avait plus cours à son époque ${ }^{4}$ (Div. , 2,77). On peut en douter car il est représenté sur un relief funéraire daté de 100 ap. J.-C., dédié par un pullarius du nom d'Atimetus, à son patron, un préfet militaire (Figure 5). Entre deux enseignes légionnaires, est figurée au sol une cage ouverte dans laquelle picorent deux poulets; la cage imposante, à claire-voie, est munie d'une anse sous laquelle passe le manche orné qui servait à la transporter; elle caractérise les fonctions du dédicant (Turcan 1988: $19 \mathrm{n}^{\circ}$ 15, pl. VIII). La tentation d'orienter le rituel était d'autant plus grande que son issue avait des conséquences capitales puisque l'on prenait les auspices pour fixer les jours fastes et néfastes qui réglaient le calendrier romain sous la République, de sorte que Pline peut dire avec raison à propos des poulets sacrés :

«Ce sont eux qui régissent quotidiennement nos magistrats, qui leur ferment ou leur ouvrent leur propre maison. Ce sont eux qui mettent en marche ou retiennent les faisceaux romains, qui ordonnent ou interdisent les batailles » $(\mathrm{NH}, \mathrm{X}, 49)$. 
Figure 4 : Auguste en augure, avec un poulet sacré, emblème de sa fonction. Autel du Vicus Sandalarius, II $\mathrm{s}$. av. J.-C. Florence, Musée des Offices

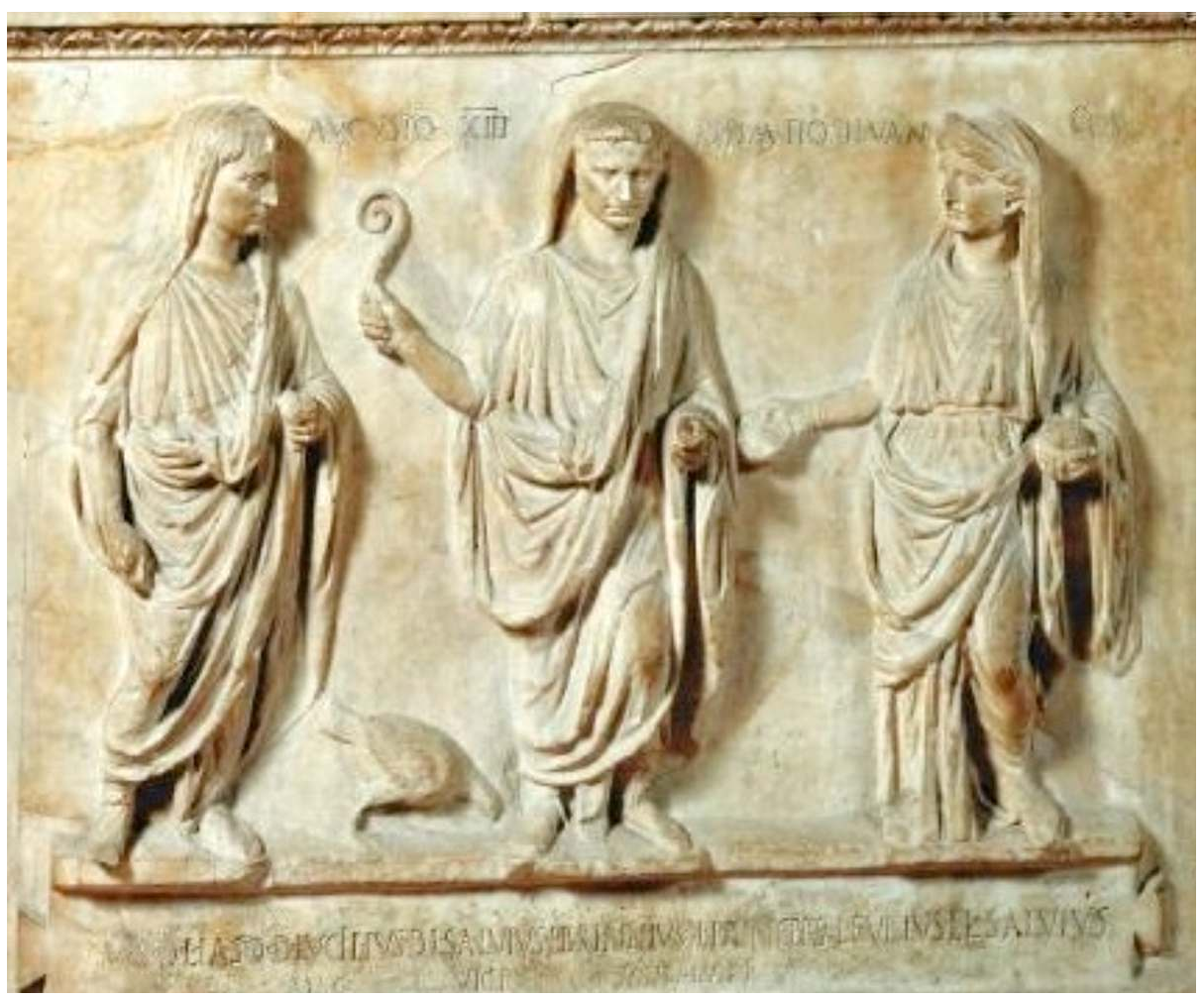

D'après Turcan 1995

Figure 5 : Cage des poulets sacrés. Relief funéraire de Grottaferrata (I), détail. Rome, Villa Albani

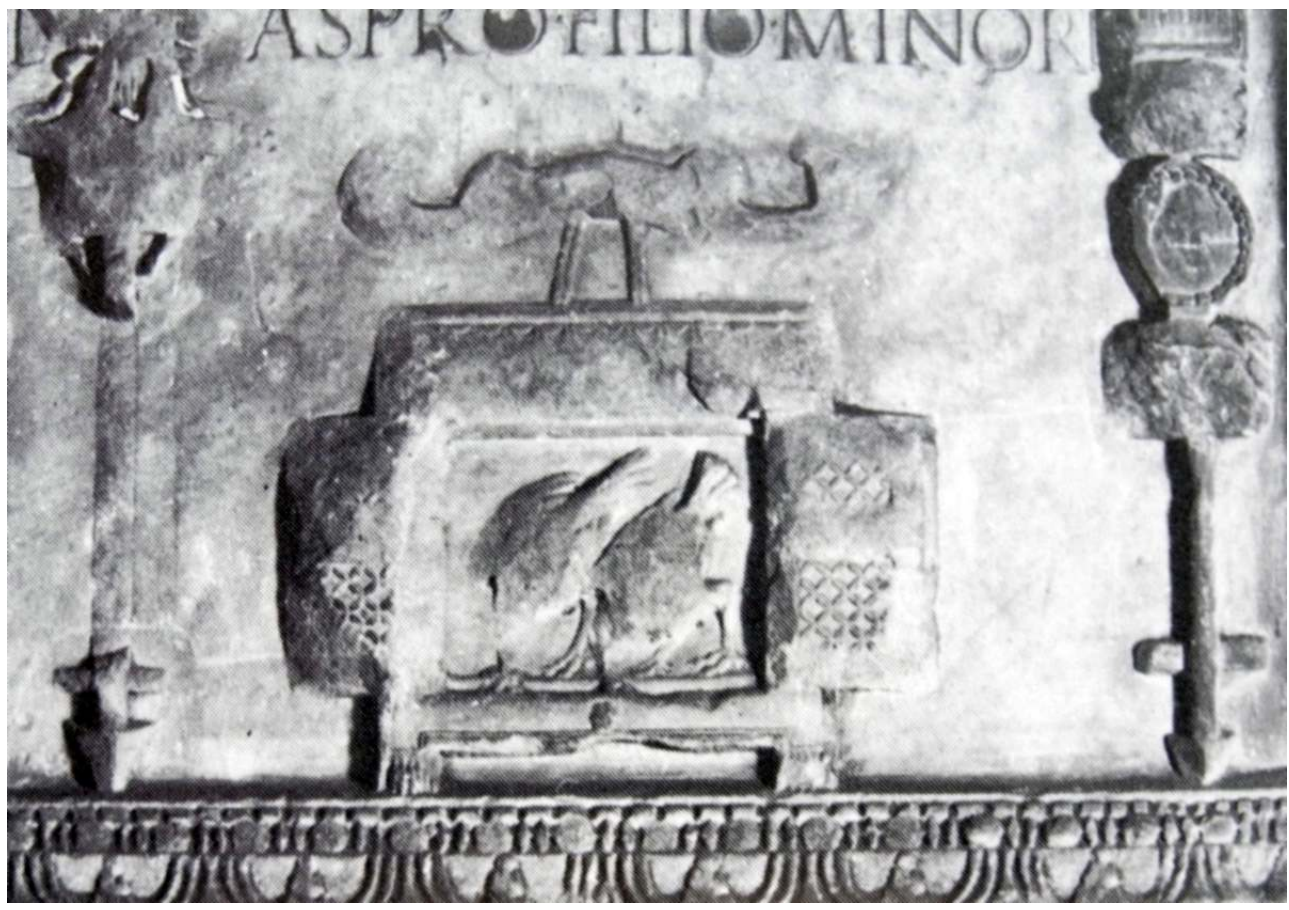

D’après Turcan 1988 
C'est ce rôle crucial des pulli avant d'engager le combat qui est à l'origine du sacrilège le plus célèbre de l'histoire romaine, dont le héros est le consul Publius Claudius Pulcher. Menant durant la première guerre punique les opérations militaires sur la côte ouest de la Sicile contre les places fortes de Lilybée et Drépan, il veut attaquer la flotte carthaginoise. On apporte la cage aux poulets sacrés, on leur propose la nourriture, qu'ils refusent; alors, fou de rage, Claudius Pulcher les jette à la mer en disant: "S'ils ne veulent pas manger qu'ils boivent. » Est-ce l'horreur du sacrilège ou le bon mot qui a fait la célébrité de l'anecdote rapportée durant toute l'Antiquité, de Cicéron à Suétone jusqu'à Valère Maxime ${ }^{5}$ ? C'est plus probablement les suites, dramatiques, de l'affaire : l'impie essuie une cuisante défaite où il perd les trois quarts de la flotte. Son collègue qui se nommait, ironie du sort, L. Junius Pullus, en prend le commandement et l'anéantit complètement en faisant stationner ses bateaux dans un mouillage dangereux. La malédiction divine est tenace...

11 La cage aux poulets sacrés, cavea, nous amène à la basse-cour où, après gallus et pullus, nous rencontrons gallina, la poule.

\section{Basses-cours d'ornement et élevage de rapport}

Comment se présente la basse-cour antique ? Peintures murales et mosaïques en offrent une image traditionnelle; mais le rapport des images à la réalité est difficile à apprécier et traduit plutôt le goût des artisans et des commanditaires pour les aspects esthétiques et pittoresques du motif. Cette basse-cour en effet a varié au cours du temps, de la République à l'Antiquité tardive, d'abord dans ses modes de gestion, de plus en plus productivistes, comme en témoignent les textes des agronomes, de Caton à Palladius (André 1981 : 127-133). Le décalage de ces sources avec les images est bien illustré par une mosaïque tardive d'Oderzo (Vénétie) datée au plus tôt de la fin du III siècle ap. J.-C. qui offre une image idyllique du poulailler (Bertacchi 1983:68-70, pl. CCXXXI, 1) (Figure 6). À l'intérieur d'une belle construction avec colonnades et balustrade, une fermière en fichu jette des grains à des volailles qui picorent devant elle: des poulardes - plutôt que des canards ${ }^{6}$ - d'une blancheur immaculée ; à gauche, deux coqs multicolores splendidement empanachés s'affrontent. Si l'architecture reflète bien la richesse des grands domaines de l'époque tardive, le mode de production est celui de la ferme des origines: vision nostalgique et idyllique, transmise par les poètes et les moralistes, d'un mode de vie autarcique où la basse-cour entre dans les fonctions de la fermière (vilicae officia) : "Qu'elle ait beaucoup de poules et d'œufs » prescrit Caton dans son traité d'agriculture ( Agr., 143, 3). 
Figure 6 : Basse-cour. Mosaïque d'Oderzo, III ${ }^{\mathrm{e}}-\mathrm{IV} \mathrm{e}$ s. ap. J.-C.

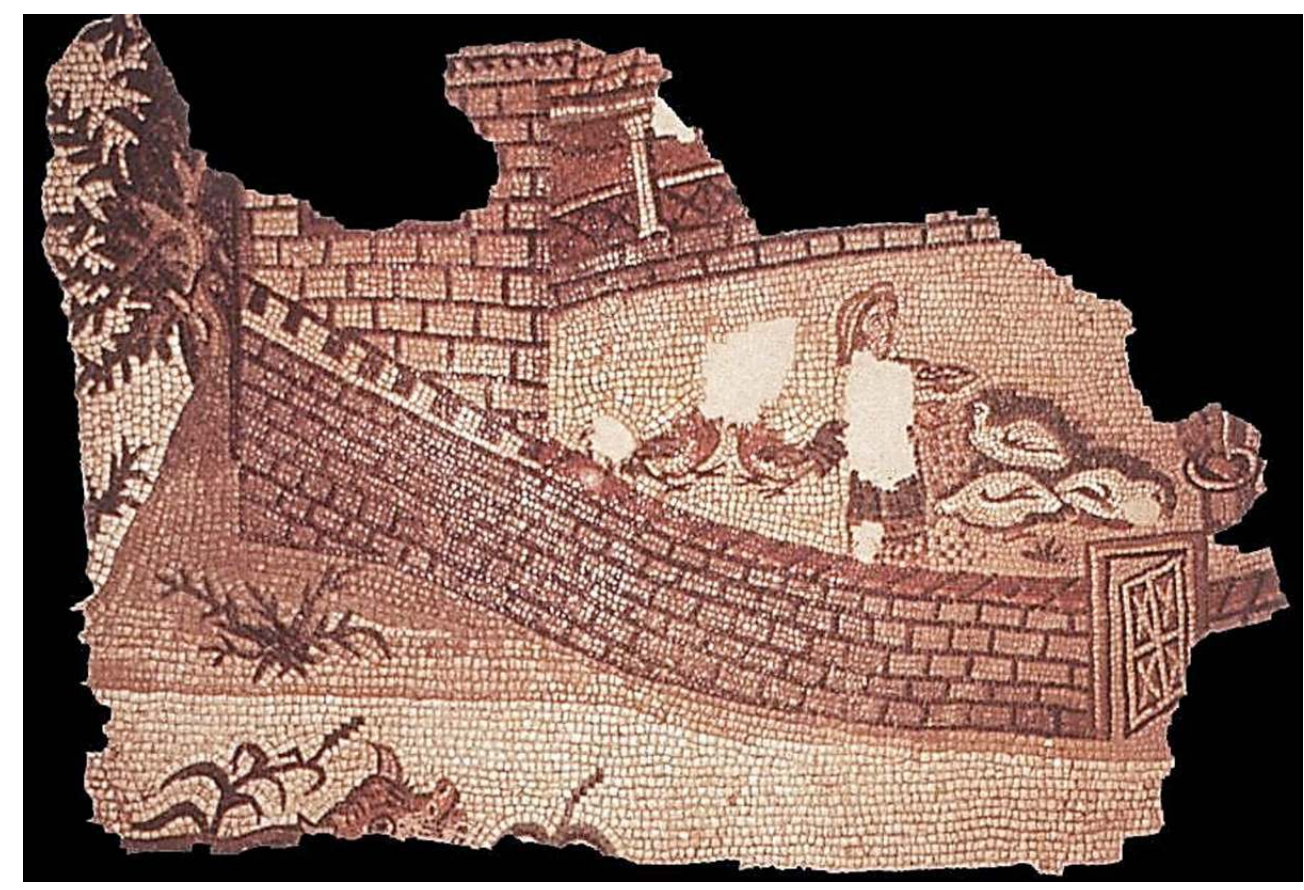

D’après Blanc \& Nercessian 1992

13 Autre décalage de la mosaïque avec la réalité : à cette époque, la basse-cour est exotique. Aux poules venues de Rhodes, sont venues s'ajouter dans l'Italie romaine des espèces étrangères acclimatées, dont les pintades. Varron (116-27 av. J.-C.) confond encore les Méléagrides, venues d'Orient, à jabot bleu, avec l'espèce venue d'Afrique, à jabot rouge, les poules de Numidie ( $R R$, III 9, 18). Les représentations figurées n'entrent pas toujours dans ces détails et insistent plutôt sur les taches du plumage qui en font un sujet de choix pour les mosaïstes: on peut citer, pour la Gaule, les deux splendides "poules de Numidie» de Saint-Romain-en-Gal (Lancha 1981: 261-274, n 395, pl. CLIIIc) (Figure 7). L'agronome Columelle, contemporain de Claude et Néron, atteste que les gallinae numidicae sont élevées communément à son époque où on les recherche pour leur goût sauvage qui au début dépaysait (André 1983: 130-131). Il faut ajouter également les variétés domestiquées, tel le pigeon, et celles qu'on capture pour les engraisser, comme les grives ou les faisans, l'oiseau du Phase qui doit son nom à sa Colchide natale; il cohabite avec un coq sur une mosaïque de la maison de la Volière à Carthage où sont figurées les diverses espèces appréciées pour leur beauté (Ben Osman 1983 : 147-148, pl. LXXXIV à LXXXVII ; Ben Abed-Ben Kahder 2003 : fig. 73) (Figure 8). C'est la basse-cour d'ornement à la mode chez les élites depuis les conquêtes et dont l'exemple le plus représentatif est la volière de Varron dans sa villa de Casinum (Res rusticae [RR], III, 5) : cet aviarium en forme de rotonde servait en même temps de triclinium, comme aussi les viviers car on aimait à voir vivants et dans toute leur beauté les espèces qu'on était en train de déguster. Les poules et coqs d'ornement, espèces exotiques réservées à la pars urbana de la villa, sont là, comme le paon, pour le plaisir des yeux. Mais les traités d'agronomie les déconseillent aux propriétaires soucieux de leurs revenus, car elles sont souvent mauvaises pondeuses et mauvaises couveuses (Columelle, VIII, 2, 12). Deux aspects essentiels car la production, comme on peut s'y attendre, vise deux objectifs : les œufs et la chair. 
Figure 7 : Pintades, « poules de Numidie ». Mosaïque de Saint-Romain-en-Gal

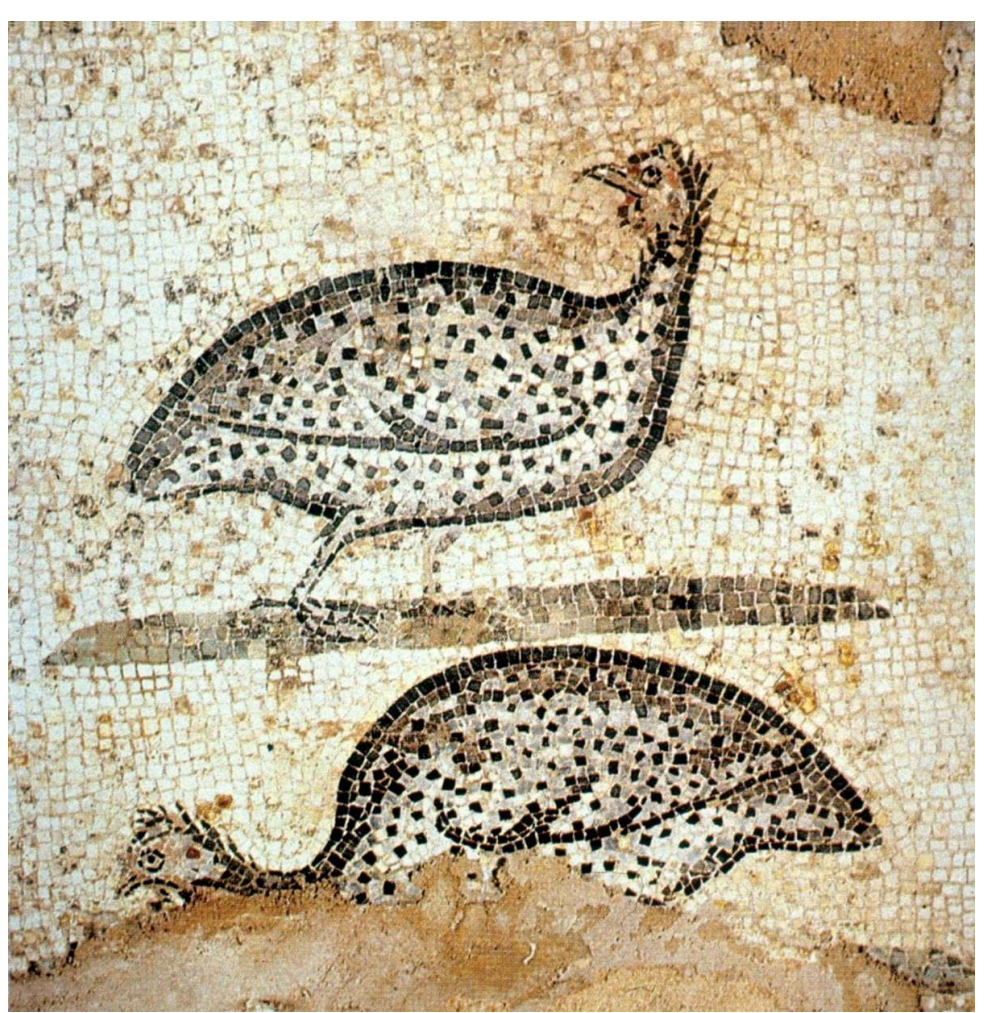

D’après Lancha 1981 
Figure 8 : Coq et faisan. Mosaïque de Carthage, colline de l'Odéon, maison dite de la Volière, détail, IV s. ap. J.-C.

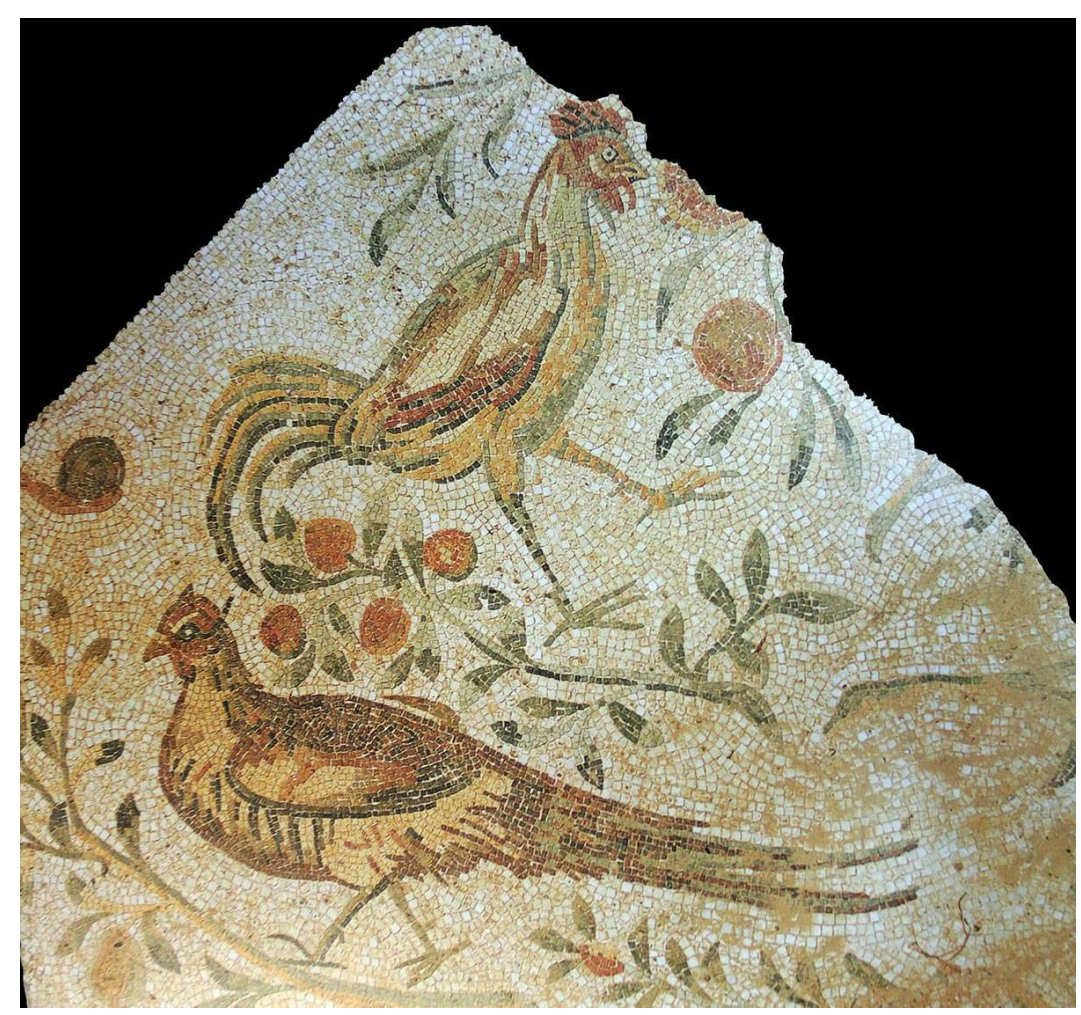

D’après Ben Abed-Ben Kahder 2003

14 Ce sont les coqs et poules qui remplissent cette double fonction, avec une répartition évidente des rôles. Le bon coq doit être d'« humeur lascive», car ses vertus combatives seront d'abord orientées vers la conquête des poules; la bonne poule, quant à elle, doit pondre et s'engraisser. Ces critères déterminent le choix des espèces à élever. Selon Columelle, il faut éviter les poules blanches, trop délicates et facilement repérables par les prédateurs, et leur préférer les variétés à plumage rouge ou brun et ailes noires ; c'est pourquoi les poules en liberté, quand elles ne couvent pas, doivent être gardées le jour par un homme assisté d'une femme ou d'un enfant (Rust. VIII, 2, 7). Cette menace des prédateurs est illustrée de façon pittoresque sur une mosaïque du Liban bordée d'un rinceau " peuplé » : une volute encadre une fermière qui court, brandissant une pierre en direction d'un renard qui s'enfuit dans la volute suivante, avec un jeune coq de belles couleurs, et non une poule, dans la gueule (Figure 9). Privée des séductions dont se pare le coq et réduite à sa fonction, la poule joue un rôle secondaire dans les représentations figurées. Les mosaïques d'Afrique du Nord, qui illustrent le couple emblématique de la basse-cour parmi les autres productions de la campagne, répètent le même schéma: le coq occupe le premier plan, affichant la polychromie flamboyante de son plumage qui cache partiellement la poule plus simplement colorée, comme on le voit sur un pavement $d^{\prime} E l$ Jem, l'antique Thysdrus ${ }^{8}$ (Figure 10). Elle récupère en revanche la première place au chapitre de la basse-cour dans les traités d'agronomie; les multiples précautions prises pour éviter que les œufs ne soient cassés au moment de la ponte expriment, parmi d'autres indices, son importance réelle dans l'économie rurale. Ces instructions détaillées ont été transmises et largement suivies jusque dans les années précédant l'industrialisation de l'élevage. Parmi les informations hétéroclites compilées par Pline, 
on relèvera, pour faciliter l'éclosion, « l'invention récente de maintenir au chaud par un feu modéré des œufs placés sur de la paille dans un endroit chaud; un homme les retourne et ils éclosent tous ensemble au jour fixé » (NH, X, 154). Curieusement, cette préfiguration de nos modernes couveuses n'est pas mentionnée par Columelle qui offre cependant l'exposé le plus complet sur cet élevage (VIII 1-7), repris dans ses grandes lignes de Varron (RR, III 9); il y explique en détail comment le mener à bien : la taille du cheptel - 200 têtes au moins - le plan et l'aménagement intérieur des poulaillers, le déroulement des différents cycles, ponte et couvaison, avec l'alimentation adaptée à chacune de ces périodes, le soin aux poussins, les remèdes aux maladies et, enfin, venant clore le chapitre, l'engraissement de la volaille.

Figure 9 : Fermière poursuivant un renard voleur de poulet. Mosaïque de l'église Saint-Christophe, Qabr Hiram (Liban), vers 575 ap. J.-C. Paris, musée du Louvre

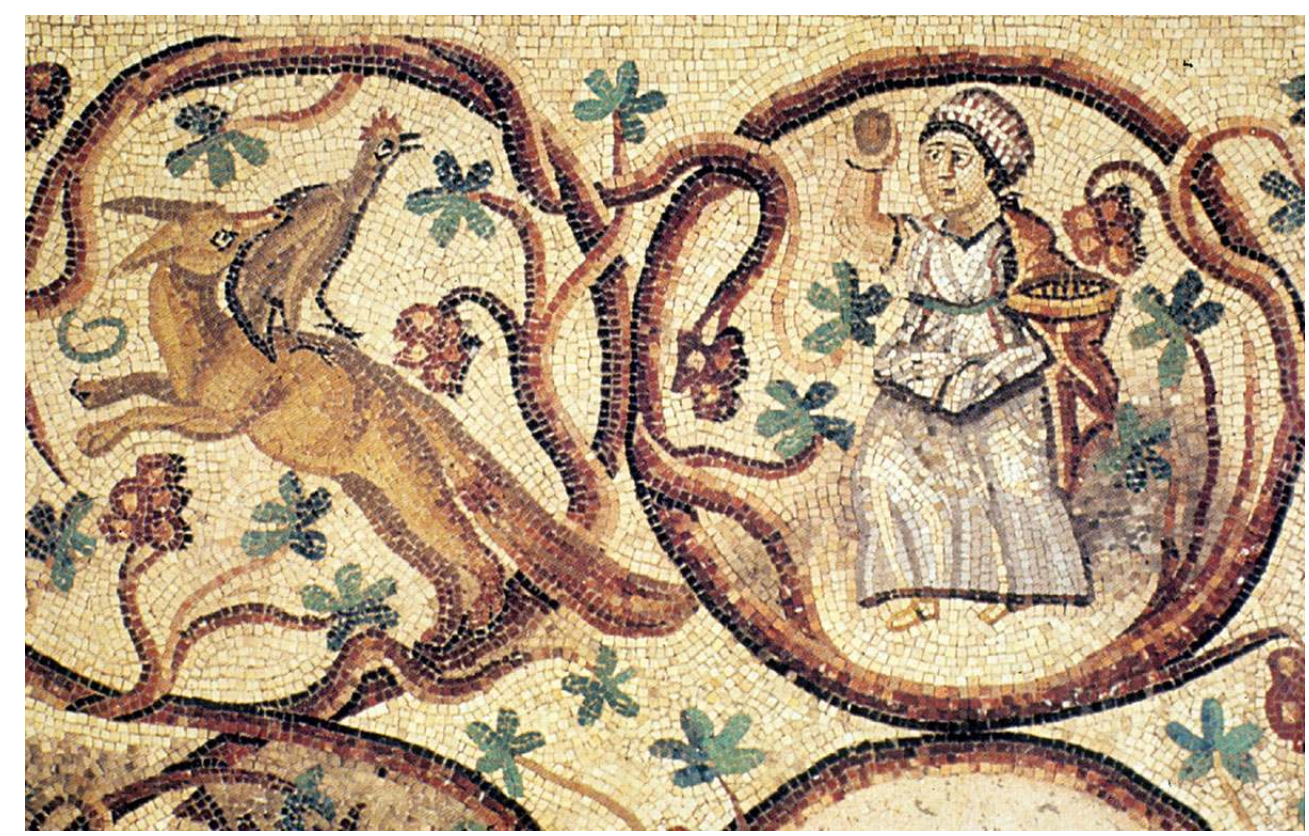

D’après Blanc \& Nercessian 1992 
Figure 10 : Gallus et gallina. Mosaïque de Carthage, maison des joueurs de dés. Tunis, musée du Bardo, inv. 3197

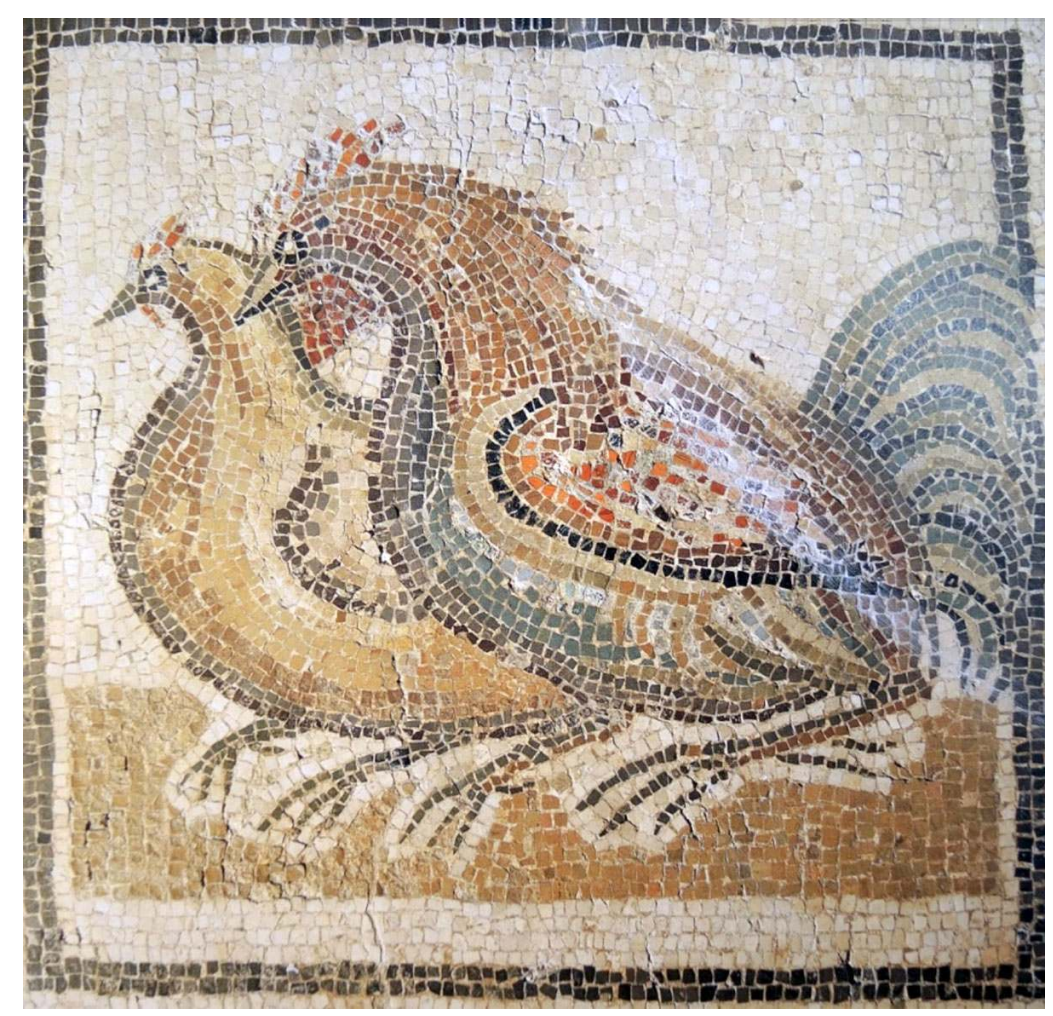

D’après Ben Abed-Ben Kahder 2003 natures mortes où sont figurées les denrées - gibiers, volailles, poissons et fruits offertes traditionnellement par les Grecs à leurs hôtes et que mosaïques et peintures représentent en trompe-l'œil sur les parois et les sols des triclinia et des cubicula. On y montre coq et poule, pattes liées comme ils furent rapportés du marché ou de la ferme. Associés à d'autres nourritures rustiques, comme du fromage frais en faisselle de jonc (Croisille 1965: 35-36, $n^{\circ}$ 31, pl. 65 et 124) (Figure 11), ils évoquent au $\mathrm{I}^{\mathrm{er}}$ siècle la table bucolique et frugale vantée par les poètes et les moralistes (Blanc \& Nercessian 1992: 207-208). Plus souvent associés à d'autres denrées de luxe, ils illustrent jusqu'à l'époque tardive, dans les pièces mêmes où ils se déroulaient, les principaux régals des banquets9

À la campagne, la consommation est d'abord associée au sacrifice : on offre un coq au Priape champêtre dont l'effigie ithyphallique, garante de fécondité, préside aux travaux des champs et aux cérémonies dionysiaques. Mais ces volailles de réforme, bonnes tout au plus à parfumer un bouillon, n'ont rien à voir avec les volailles élevées pour la consommation. Ce sont les Déliens qui auraient les premiers engraissé des poules : « Ainsi naquit la passion ruineuse de manger des volailles grasses et arrosées de leur jus » (Pline, $N H, \mathrm{X}, 139)$. L'austère Caton, explique déjà dans son traité comment engraisser - farcire - à la ferme les poules et les oies : on les enferme jeunes et on les gave à la main deux fois par jour de boulettes de farine de blé et d'orge mouillées d'eau (Agr. LXXXXVIII, 89). Chez Varron $(R R, I I I, 9)$, on engraisse encore à la ferme mais non plus à la main, et le régime se perfectionne avec une alimentation plus raffinée, à base de pain émietté dans de l'eau et du bon vin parfumé, pour rendre la chair grasse et tendre en vingt jours. Avec Columelle (

Revue d'ethnoécologie, 12 | 2017 
Rust. VIII, 7), on voit se mettre en place des techniques déjà modernes : enfermées au chaud et dans l'obscurité, immobilisées dans une cage individuelle qui ne laisse dépasser que tête et croupion, les poules sont nourries avec des boulettes d'orge auxquelles peuvent s'ajouter blé, miel et vin pour mieux attendrir la chair. Quant à Palladius, trois siècles plus tard, il détaille davantage le gavage des oies pour obtenir des foies gras, technique plus complexe mais plus lucrative (RR, I, 30).

Figure 11 : Gallus et gallina. Peinture murale de Pompéi. Naples, Musée archéologique national

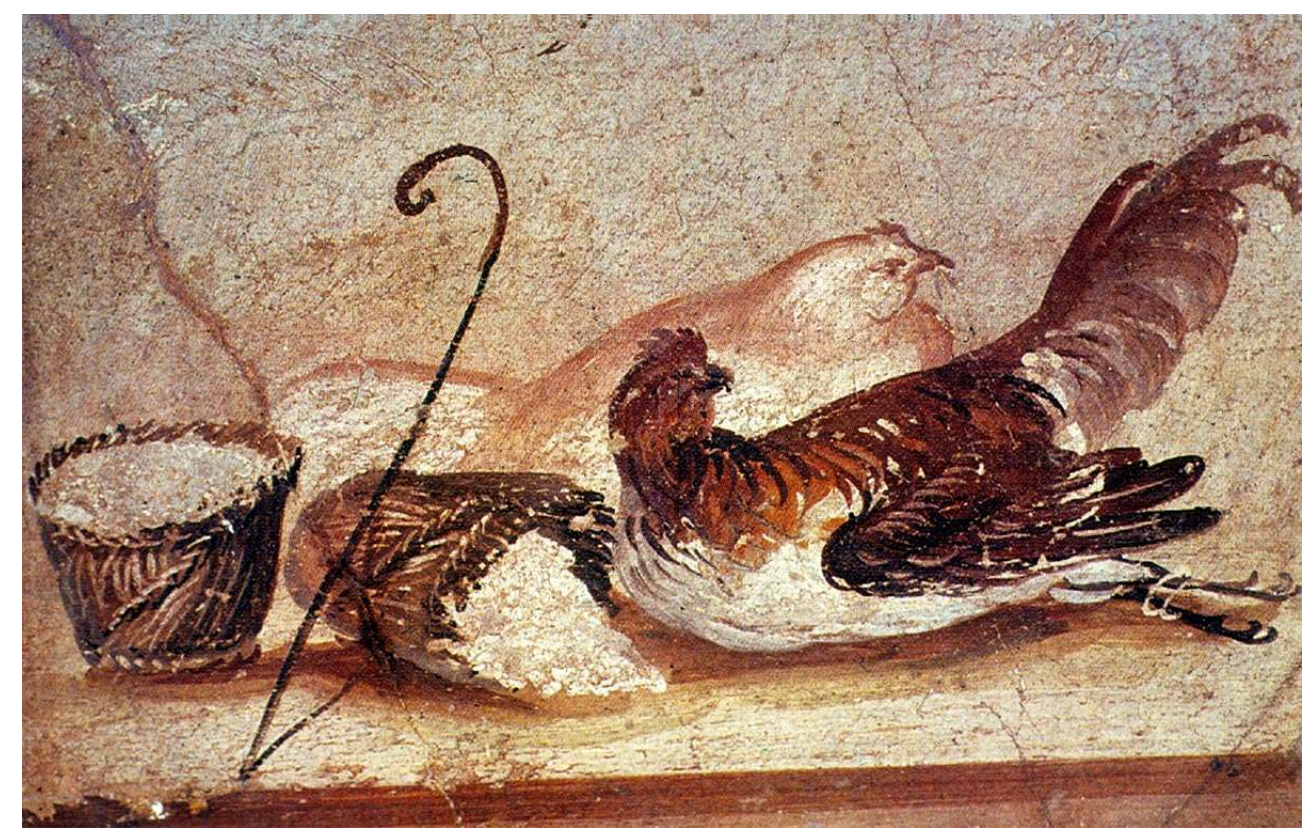

D'après Blanc \& Nercessian 1992

\section{Alimentation et cuisine}

17 Si Columelle consacre un chapitre entier à l'engraissement des poules ( $R R$, VIII, 7), il observe néanmoins que cette opération est plutôt le fait d'un spécialiste, le fartor ${ }^{10}$. Celuici est généralement installé à proximité des marchés citadins où sont commercialisés ces produits de luxe que sont poules, oies, grives et faisans engraissés. Une peinture de Pompéi ornant le macellum, malheureusement très effacée, figure justement une scène de marché avec l'étal d'un volailler, proposant volailles abattues ou vivantes (Croisille 1965 : $97, \mathrm{n}^{\circ} 268, \mathrm{pl} .77,147$ ) (Figure 12). Au-dessus du banc, on distingue, à côté d'un chapelet de grives (?), deux volatiles déjà préparés, accrochés par les pattes, cou pendant ; dessous, une grande cage oblongue d'osier, percée d'ouvertures, est posée au sol; à droite une grosse volaille au plumage multicolore est couchée, pattes liées. 
Figure 12 : Détail de l'éventaire d'un volailler, peinture murale. Pompéi, macellum, VII 9, 4-12

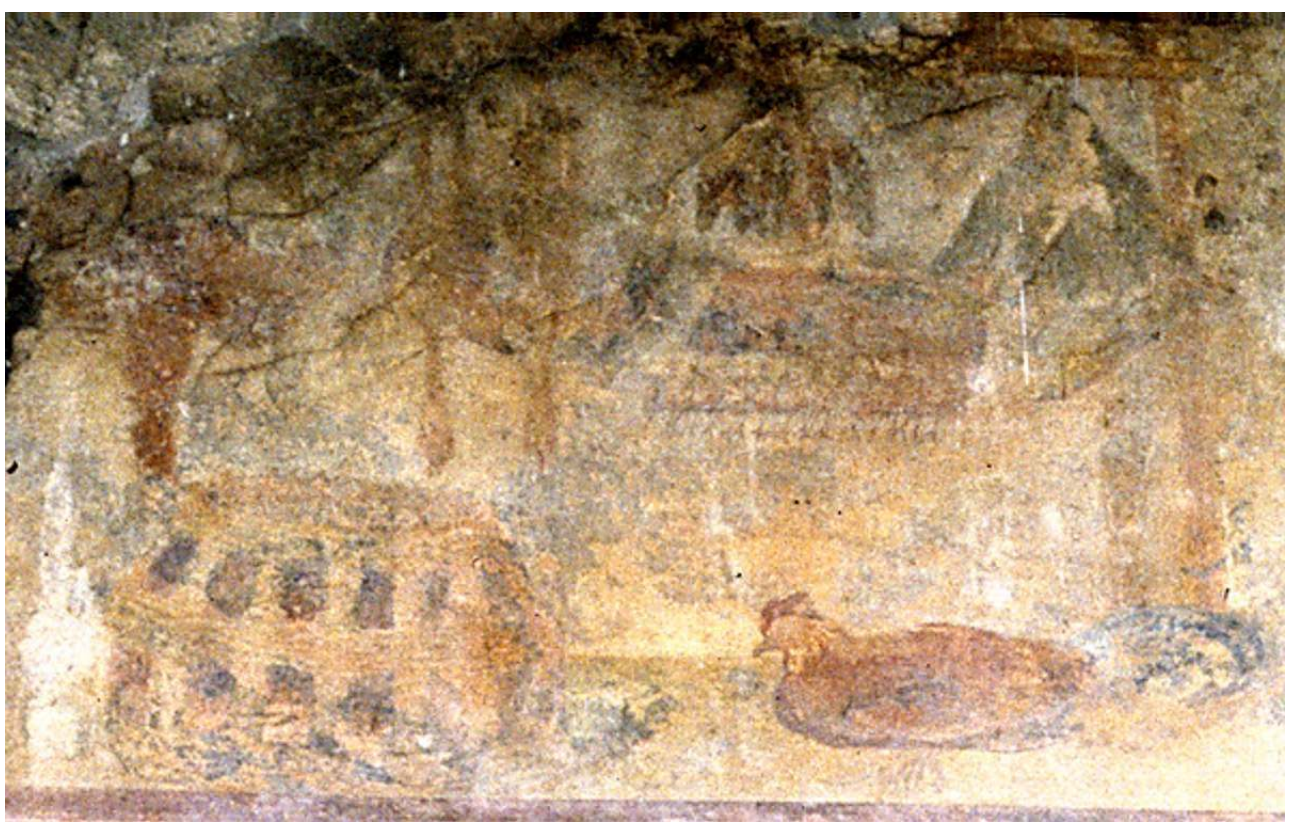

Cliché F. Monier

La consommation des gallinacés est bien attestée dans tout l'Empire, confirmée localement par les fouilles archéologiques et les études archéozoologiques. Les sources écrites et l'iconographie nous apportent des informations complémentaires sur son statut dans la cuisine, cuisine aristocratique, il va sans dire. Les préparations communes nous échappent, à la différence du porc, dont le salage et la fumaison font une provision de garde plus accessible, régulièrement présente dans les régals populaires. La volaille n'est mentionnée que dans le contexte du convivium où les mets de prestige s'accordent aux visées sociale et politique de la réunion. Une poule engraissée - gallina altilis - est servie dans le banquet de prise de fonction de Lentulus comme Flamine de Mars au début du $\mathrm{I}^{\mathrm{er}}$ siècle av. J.-C. (Macrobe, Sat., II, 9) ; elle est présentée au premier service, avec des huîtres et des asperges, ce qui indique assez qu'elle prend place parmi les plats de luxe à cette époque. Elle figure d'ailleurs dans les Lois somptuaires, au titre des dispositions visant à limiter la dépense maximale autorisée par banquet (Coudry 2004). La lex Fannia en 161 av. J.-C. prescrit de ne servir qu'une seule poule par repas, non engraissée, mais pour l'éluder, nous dit Pline (HN, X, 139-140), on imagina de substituer aux poules de jeunes coqs nourris avec des aliments trempés dans du lait. La poularde constitue encore un mets de choix sous Domitien puisqu'on l'offre aux Saturnales comme l'indique ce distique de Martial (XIII, 59), censé accompagner son envoi : « La poule est facile à engraisser avec une farine douce. Elle s'engraisse aussi dans les ténèbres. Ingénieuse est la gourmandise ». Les xenia qui figurent avec des poules ou chapons, accrochés dans la resserre, déjà plumés et prêts à être cuisinés, donnent à voir de façon réaliste ces régals aussi convoités que ruineux ${ }^{11}$ (Figure 13). 


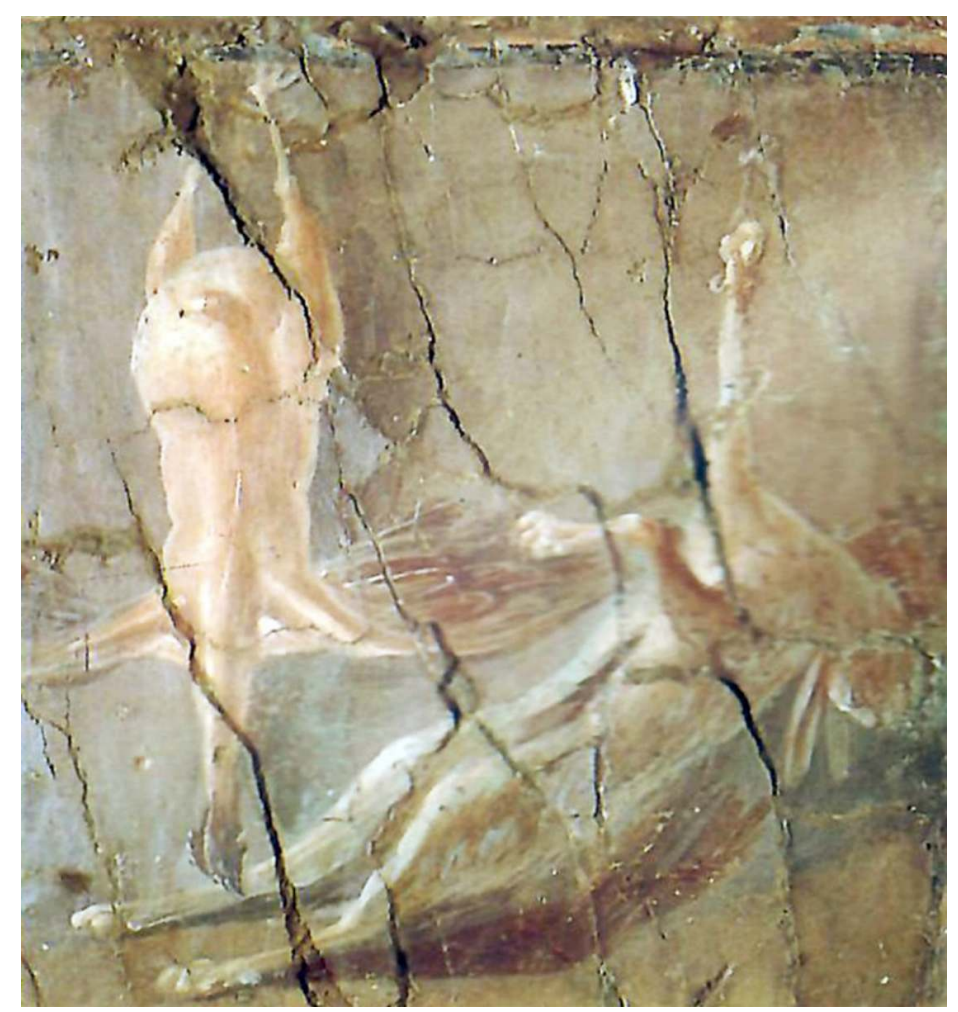

D’après Blanc \& Nercessian 1992

Dans l'édit du Maximum promulgué en 301 par l'empereur Dioclétien, fixant le tarif des produits et des services dans l'Empire, la poule ne figure plus parmi les volailles engraissées. À 60 deniers la paire, le poulet arrive derrière la poule faisane et l'oie, payées 100 deniers, mais le double lorsqu'elles sont engraissées (Éd. Diocl., 4, 17-23); toutefois perdrix et tourterelles, même engraissées, sont encore moins coûteuses. Et les mosaïques des riches villae tardives continuent à figurer le couple emblématique du coq et de la poule parmi les xenia de poissons, gibiers, asperges et autres régals fastueux dans les mosaïques de triclinium (Balmelle 1990).

Le traité de cuisine d'Apicius offre une vision singulièrement plus riche et nuancée de la place de la poule dans la cuisine. Rappelons que le De re coquinaria est un recueil du Iv siècle auquel est accolé le nom d'Apicius sans qu'on puisse faire de lien sûr avec un personnage historique réel et bien daté (Blanc \& Nercessian 1999). En admettant même qu'il s'agisse du célèbre gastronome proche de Tibère, réputé pour ses extravagances, le texte qui nous est parvenu est une compilation, construite par apports successifs, d'origines variées, durant quatre siècles au moins. Sur les 468 « recettes » qu'il contient, un grand nombre ne sont pas des préparations culinaires à proprement parler, mais des procédés de conservation, formules thérapeutiques et prescriptions diverses. Les recettes qui concernent notre sujet sont réunies dans le chapitre VI, sous le titre Trophetes, le terme grec correspondant au latin fartor, l'engraisseur de volailles. Après sept paragraphes consacrés aux divers oiseaux, palombes, faisans, oies et autres volatiles de luxe, la rubrique VIII regroupe seize recettes (236-251) sous l'intitulé «in pullo», terme à ne pas traduire littéralement. Dans ce traité de gastronomie où les épices exotiques les 
plus coûteuses sont déversées à foison, il s'agit sans aucun doute de volailles engraissées, poulardes et chapons ${ }^{12}$. Les préparations sont aussi complexes que sophistiquées. On vide la bête par le croupion, mais aussi par le cou, on la pare « en carré »; elle peut cuire en deux fois, bouillie puis rôtie; on la farcit de dattes, de pignons, de cervelle, d'olives; on l'accompagne de sauces qui rassemblent une dizaine d'ingrédients tant épices, aromatiques que vin, miel, garum et vinaigre; sauces dont on arrose la volaille préalablement incisée avant de la rôtir ou dans lesquelles elle est mise à cuire et mijoter, ou dont on l'arrose avant de servir et que l'on présente parfois à part dans une belle pièce d'orfèvrerie. On préfère garder la volaille entière, pour le plaisir des yeux et l'attrait du spectacle : des esclaves spécialisés, qui se signalent par leur habileté à lever les filets, la découpent devant les convives. Une mosaïque d'El Jem nous conserve l'image d'une poule plumée et bridée, prête à être cuisinée (Figure 14). Cette mise en scène de la volaille dont nous avons héritée va de pair avec le goût général des Romains pour les pièces de belle taille, illustré à l'autre extrémité de l'Empire par une découverte effectuée en Germanie supérieure, dans la vallée du Neckar à Mundelsheim (Baden-Württemberg) ${ }^{13}$ (Figure 15); il s'agit d'un grand couvercle de plat en bronze orné d'une somptueuse composition ; une couronne de douze volailles bridées entoure six cochons de lait rôtis disposés en cercle autour d'un lièvre, le clou de cette spectaculaire pièce montée. Cette recherche ostentatoire des volailles les plus énormes explique sans doute une préférence pour l'oie engraissée et son foie, régal plus souvent évoqué dans les textes.

Figure 14 : Volaille bridée. Mosaïque d'El Jem (Tunisie)

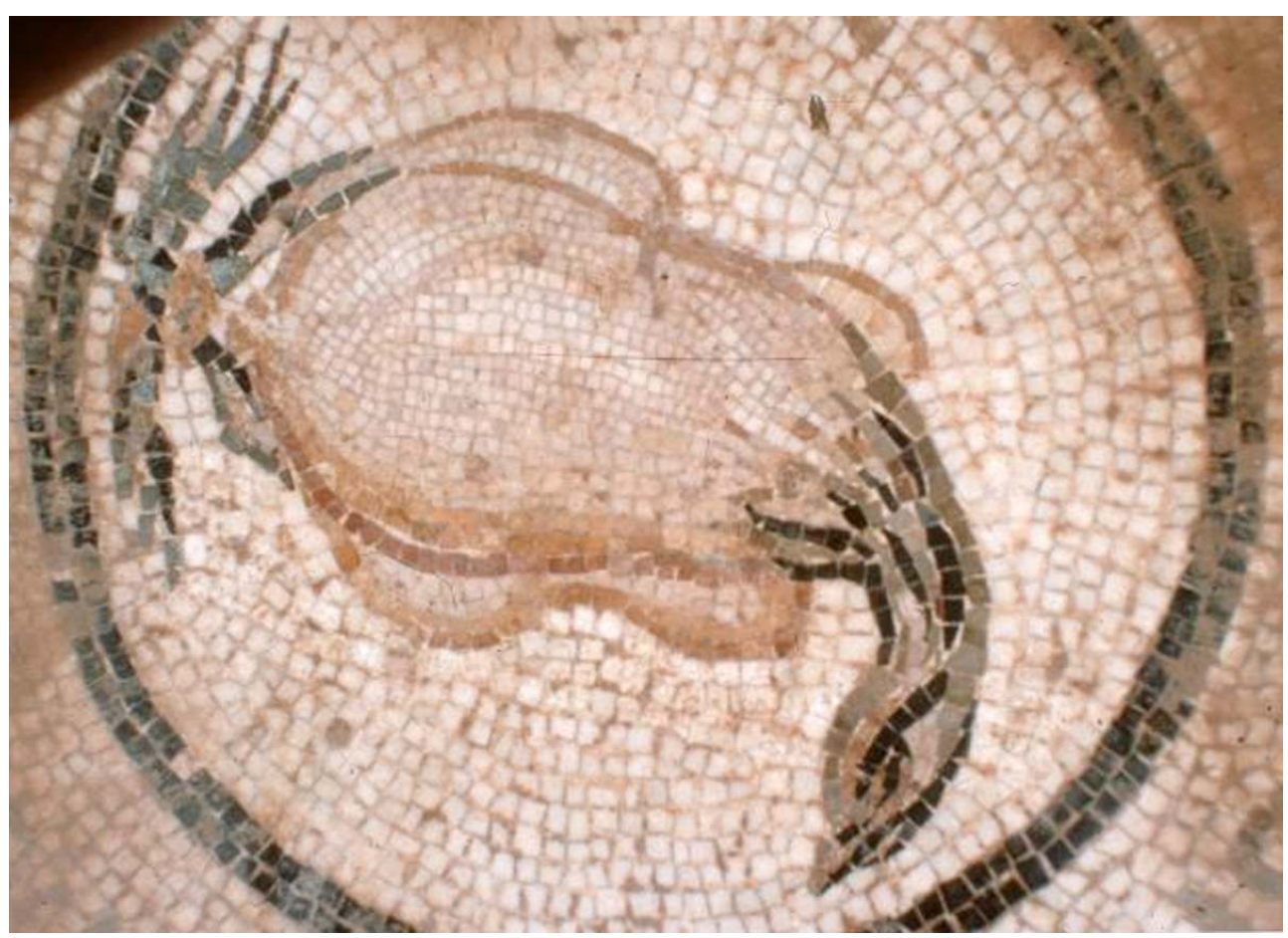

Cliché Centre H. Stern, CNRS, UMR 8546 
Figure 15 : Volailles bridées, marcassins et lièvre. Couvercle de plat. MundesIsheim (Allemagne)

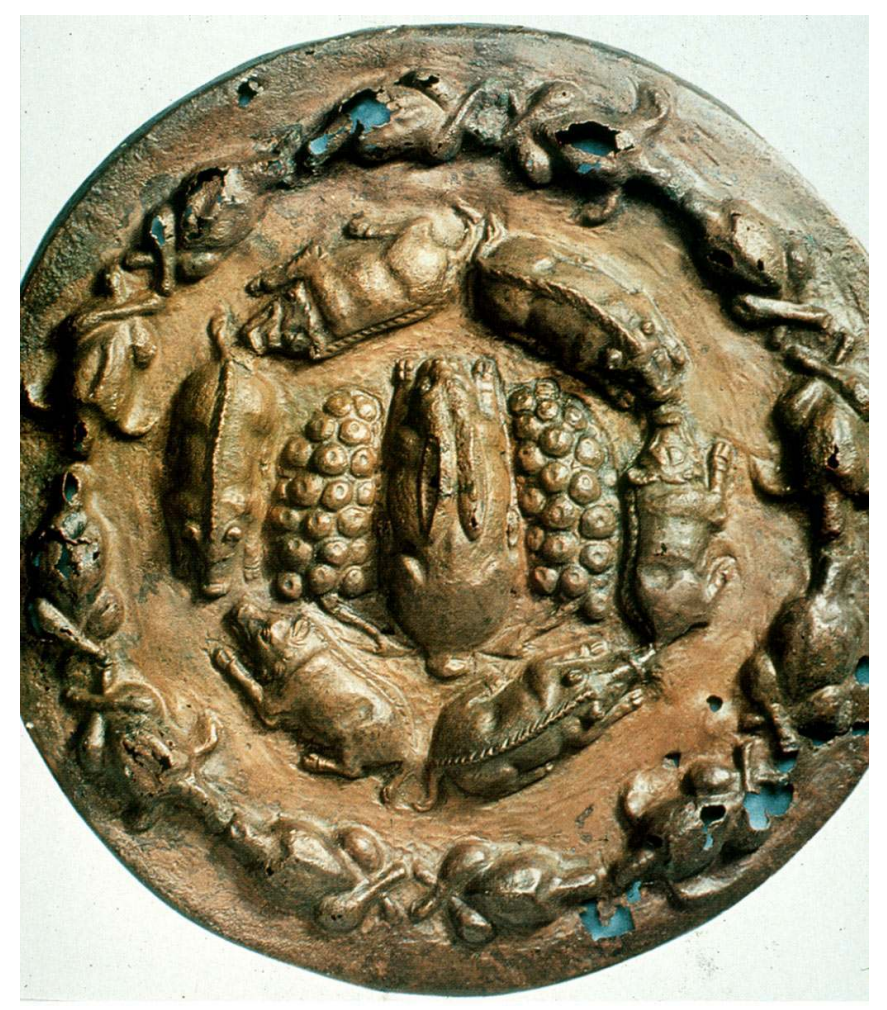

D’après Blanc \& Nercessian 1992

21 Un aspect plus problématique est le statut des œufs, qui a beaucoup varié de la République à l'époque impériale tardive. Ils sont utilisés avec parcimonie dans les pâtisseries offertes aux dieux, dont Caton donne les recettes (Agr., LXXXIV, 75 ; XCIII, 84), et ils sont présents dans les xenia. Une peinture pompéienne les associe à un chapelet de grives et une œnochoé d'argent (Croisille 1965 : 97 n² 268, pl. 102, 193) (Figure 16). Le De re coquinaria comporte trois recettes pour assaisonner les œufs durs, frits ou mollets ; elles sont classées dans le chapitre Politeles, c'est-à-dire le [cuisinier] somptueux. Or cette partie constitue probablement le cœur du recueil et doit remonter au $\mathrm{I}^{\mathrm{er}}$ siècle ap. J.-C. si l'on en juge à la hiérarchie des mets : on y trouve les loirs et les tétines de truie qui, servis chez Trimalcion dans le Satiricon, sont passés de mode à l'époque tardive. Traditionnellement, les œufs sont servis en entrée, d'où l'expression proverbiale ab ovo ad mala, littéralement de l'œuf jusqu'aux pommes, pour signifier du début à la fin. Les fouilles ont livré les coquetiers et surtout les cuillers d'argent - cochlaear - à la forme caractéristique, cuiller d'un côté, pique à escargots de l'autre, qui servaient à les déguster (Blanc \& Nercessian 1992 : 135-137) : on voit par là que c'est moins le produit lui-même que son service qui lui confère ce statut particulier, même si l'œuf mangé à la coque est un privilège de nanti, comme tous les produits frais à l'époque. 


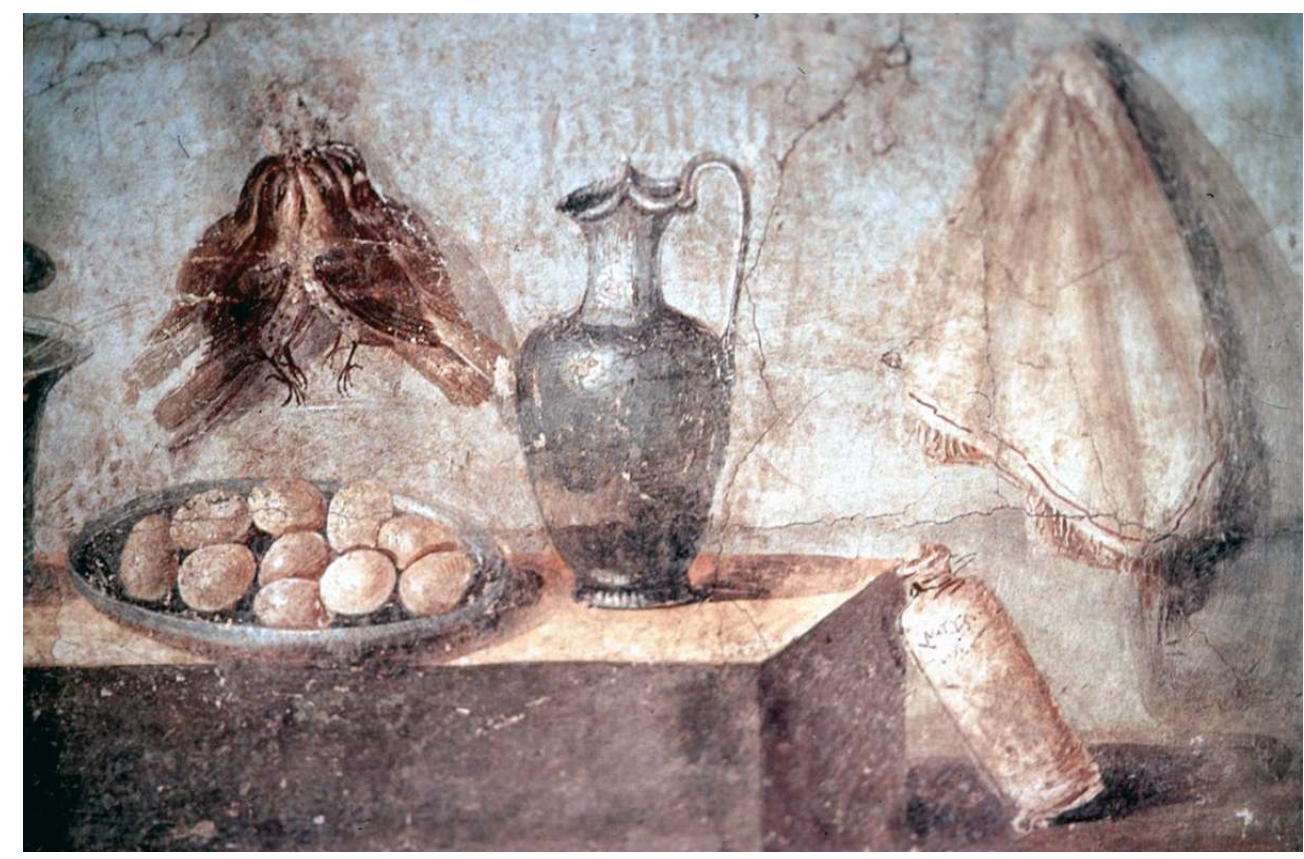

D’après Blanc \& Nercessian 1992

L'œuf entre aussi dans la composition d'un autre mets qui tient une large place dans le recueil, la patina, qui doit son nom au récipient - un plat à four - dans lequel il est préparé. Le De re coquinaria en comporte trente-sept recettes, placées dans le chapitre IV qui regroupe non pas un type d'aliment, mais des préparations cuisinées, dont la patina est la plus facile à cerner car elle se caractérise par une liaison à l'œuf. On peut la confectionner avec toutes sortes de produits - viande, poisson, légumes, fruits - et elle a une large extension chronologique : elle figure dans le banquet déjà cité de Lentulus où sont servies parmi les entrées trois recettes différentes, patina d'huîtres, de poissons et de tétines de truies; on trouve encore une patina de soles dans les Excerpta de Vinidarius, un abrégé d'Apicius de la fin $\mathrm{du}^{\mathrm{e}}$ ou du début du vi siècle.

Conclure avec l'œuf permet de proposer une liaison un peu factice entre les membres d'une famille très hétérogène dans son aspect et ses fonctions. On notera cependant que c'est la figure la plus effacée, que distingue brièvement un rôle divinatoire contesté, qui s'impose et triomphe dans le lexique moderne : ni gallus, ni gallina, mais pullus ${ }^{14}$. Le terme qui désigne littéralement le petit de l'animal - de pullare, germer - exprime au mieux le concept de croissance : une étymologie fautive de Festus ${ }^{15}$ rapproche pullus de puls, la bouillie, nourriture des poulets sacrés (Valère Maxime, II, 5,5), aliment par excellence de la ferme et de la basse-cour. Sans aller plus loin dans l'étude lexicale, constatons du moins que la proximité de consonance entre les deux mots suggère au mieux la fécondité et la fonction nourricière de la poule. 


\section{BIBLIOGRAPHIE}

André J. 1981 - La cuisine et l'alimentation à Rome. Paris, Collection des Universités de France, 252 p.

Balmelle C. 1990 - Quelques images de mosaïques à xenia hors de Tunisie. In : Balmelle C., Ben Abed-Ben Khader A., Ben Osman W. et al. Recherches franco-tunisiennes sur la mosaïue de l'Afrique antique. Vol. I., Xenia. Rome, École Française de Rome, coll. EFR 125 : 51-66.

Baratte F. 1978 - Mosaïques romaines et paléochrétiennes du Musée du Louvre. Paris, RMN, 169 p.

Ben Abed-Ben Khader A. 2003 - Image de pierre : la Tunisie en mosaïque. Paris, Ars latina, 547 p.

Ben Osman W. 1983 - Étude des pavements de la Villa de la Volière. In : Mosaïque : Recueil d'hommages à Henri Stern. Paris, Recherche sur les civilisations : 147-156.

Bertacchi L. 1983 - Ricomposizione del mosaico opitergino con villa rustica. In : Mosaïque : Recueil d'hommages à Henri Stern. Paris, Recherche sur les civilisations : 65-73.

Blanc N. \& Nercessian A. 1992 - La cuisine romaine antique. Grenoble, Glénat-Faton, 223 p.

Blanc N. \& Nercessian A. 1999 - Apicius. In : Encyclopaedia Universalis. Paris www.universalis.fr Bragantini I. \& Sampaolo V. 2010 - La pittura pompeiana, Museo Archeologico Nazionale di Napoli. Naples, Electa, 557 p.

Bruneau P. 1965 - Le motif des coqs affrontés dans l'imagerie antique. Bulletin de Correspondance hellénique $[\mathrm{BCH}] 89: 90-121$.

Caton [1975] - De agricultura. Paris, Collection des Universités de France.

Cicéron [1933] - De natura deorum. Harvard, Harvard University Press, Loeb classical Library.

Cicéron [1923] - De divinatione. Harvard, Harvard University Press, Loeb classical Library.

Collezioni 1989 - Le collezioni del Museo Nazionale di Napoli, vol. 1 (1), I mosaici, le pitture, gli ogetti di uso quotidiano, gli argenti, le terrecotte invetriate, i vetri, i cristalli, gli avori. Archivio fotografico Pedicini (Naples). Rome, De Luca, 241 p.

Columelle [1954] - De re rustica. Harvard, Harvard University Press, Loeb classical Library. Coudry M. 2004 - Loi et société : la singularité des lois somptuaires de Rome. Cahier du Centre Gustave Glotz 15 : 135-171.

Croisille J.-M. 1965 - Les natures mortes campaniennes : répertoire descriptif des peintures de nature morte du Musée national de Naples, de Pompéi, Herculanum et Stabies. Bruxelles, Berchem, collection Latomus 76, $126 \mathrm{p}$.

Croisille J.-M. 2015 - Natures mortes dans la Rome antique. Naissance d'un genre artistique. Paris, Éditions Picard, 160 p.

Dunbabin K.M.D. 1978 - The Mosaics of Roman North Africa: Studies in iconography and patronage. Oxford, Clarendon Press, 303 p. (Oxford monographs on classical archaeology : 16).

Dumont J. 1988 - Les combats de coqs furent-ils un sport ? Pallas 34 : 33-44.

Élien [1991] - Histoire variée. Paris, Collection des Universités de France.

Eschine [1927-1928] - Contre Timarque. Paris, Collection des Universités de France. 
Eschyle [1925] - Les Euménides. Paris, Collection des Universités de France.

Guillaumont F. 2006 - Le "De divinatione" de Cicéron et les théories antiques de la divination. Bruxelles, Berchem, 395 p. (Latomus ; 298).

Hoffmann H. 1974 - Hahnenkampf in Athen: zur Ikonologie einer attischen Bildformel. Revue archéologique 2 : 195-220.

Lancha J. 1981 - Recueil général des mosaïques de la Gaule. 3. Province de Narbonnaise. 2. Vienne. Gallia. Supplément 10, $317 \mathrm{p}$.

Lissarrague F. 2013 - La place des mots dans l'imagerie attique. Pallas 93 : 69-79.

Macrobe [2011] - Saturnalia. Harvard, Harvard University Press, Loeb Classical Library.

Martial [1930-1934] - Épigrammes, I-II. Paris, Collection des Universités de France.

Meulder M. 1999 - Une trifonctionnalité indo-européenne dans Valère Maxime. Revue internationale des droits de l'Antiquité 46 : 315-368.

Palladius [1976] - Traité d'agriculture, I. Paris, Collection des Universités de France.

Platon [1956] - Les Lois, VII-X. Paris, Collection des Universités de France.

Pline l'Ancien [1961] - Naturalis Historia, X. Paris, Collection des Universités de France.

PPM, EAA 1990-2003 - Pompei, pitture e mosaici. Enciclopedia dell'Arte Antica. Rome, Istituto della enciclopedia italiana, 11 vol. ill., $11337 \mathrm{p}$.

Rashed M. 2012 - La mosaïque des philosophes de Naples : une représentation de l'académie platonicienne et son commanditaire. In : Noirot C. \& Ordine N. (Ed.), Omnia in Uno, Hommage à Alain-Philippe Segonds. Paris, Les Belles Lettres : 27-49.

Strocka V.M. 1991 - Casa del Labirinto (VI 11, 8-10). Häuser in Pompeji. 4. Munich, Himmer Verlag, $143 \mathrm{p}$.

Tammisto A. 1997 - Birds in Mosaics: A Study on the Representation of Birds in Hellenistic and RomanoCampanian tessellated Mosaics to the early augustan Age. Rome, Institutum Romanum Finlandiae, 524 p. (Acta Instituti Romani Finlandiae ; 18).

Turcan R. 1988 - Religion romaine, 2. Le culte. Leyden, J. Brill, Iconography of religions, section XVII, 1, 2, 39 p, 52 p. de planches.

Turcan R. 1995 - L'art romain dans l'histoire : six siècles d'expressions de la romanité. Paris, Flammarion, $383 \mathrm{p}$.

Varron [1997] - Économie rurale, III. Paris, Collection des Universités de France.

Wheeler E.L. 2008 - Pullarii, Marsi, Haruspices, and Sacerdotes in the Roman Imperial Army. In : Schellenberg H.M., Hirschmann V.E., Krieckhaus A. \& Lapie P. (Ed.), A Roman Miscellany. Essays in Honour of Anthony R. Birley on his Seventieth Birthday. Gdansk, Foundation for the Development of Gdánsk University : 3-21. (Monograph series Akanthina ; 3).

Xénophon [1961] - Le banquet. Paris, Collection des Universités de France.

\section{NOTES}

1. Sur l'origine géographique de l'animal et son introduction en Grèce, voir Dumont 1988 : 34-35.

2. Pompéi, villa de Siminius Stephanus. Naples, Musée archéologique national, inv. 124545. Le collezioni $1989: 116 \mathrm{n}^{\circ} 15$ et fig. 
3. Voir l'explication de Festus, infra n. 15.

4. Outre le relief funéraire d'Atimetus (fig. 4), d'autres témoignages épigraphiques, trouvés dans des sites militaires, contredisent Cicéron (Wheeler $2008: 5-7$ ).

5. Cicéron narre l'épisode dans le De natura deorum (II, 7) et y revient dans le De divinatione (I, 77-78) ; le dossier complet des textes est donné dans Meulder 1999.

6. La tache sombre sur laquelle se détachent les volatiles pourrait figurer de l'eau selon Bertacchi 1983.

7. Mosaïque à rinceau peuplé, $1^{\text {re }}$ rangée, médaillons a et $b$; la $3^{\mathrm{e}}$ volute est occupée par une pintade, entourée de ses petits qui picorent. Datée de 575 ap. J.-C. (inscription). Paris, musée du Louvre, inv. MA 2230-2236. Baratte 1978 : 132-145, n 55, part. 135, fig. 143.

8. Mosaïque «des Joueurs de dés" d'El Jem, conservée à Tunis, musée du Bardo, inv. 3197 : Dunbabin 1978, 125, 170, pl. 118. Autre exemple du même schéma : Mosaïque 1983 : pl. IX, 2.

9. Sur les xenia et leur problématique, voir l'ouvrage désormais classique pour la mosaïque ( Mosaïque 1983), à quoi il faut ajouter pour la peinture murale Croisille 2015.

10. De far, la céréale utilisée pour l'engraissement non seulement des poules, mais aussi de tous les volatiles que l'on gavait.

11. Naples, Musée archéologique national, inv. 8647. Herculanum, maison des Cerfs. Croisille 1965 : 40-41, n 46 A, pl. 78 ; Bragantini \& Sampaolo 2010 : 376, nº 175 et fig.

12. Le terme de chapon (capo) est employé une fois (IV, 167), ce qui témoigne de plusieurs états du manuscrit; de même, gallina n'apparaît qu'une fois au chapitre des légumes dans une recette de gourdes destinée à accompagner la poule (III, 80).

13. Trouvé en 1937 sur le site d'une villa rustica, daté des $\mathrm{II}^{\mathrm{e}}-\mathrm{III}{ }^{\mathrm{e}}$ siècles ap. J.-C.: Stuttgart, Württembergisches Landesmuseum, inv. 136.1 ; diam. : $40 \mathrm{~cm}$. Notiziario di scavi, scoperte e studi, relativi all'impero romano, BullMuseoImpRom, IX, 1838-XVI-XVII (appendix BollCom XLVI), 105-106, pl. D.

14. Dans les Excerpta de Vinidarius (Ia), on rencontre le terme significatif de pullina.

15. Festus Grammaticus, De significatione verborum, XIV : «PULS potissimum dabatur pullis in auspiciis, quia ex ea necesse erat aliquid decidere, quod tripudium faceret; id est terripuvium : puvire enim ferire est. » Traduction: On donnait de préférence dans les auspices de la bouillie aux poulets, parce qu'il en tombait nécessairement une partie qui faisait un certain bond, c'est-àdire un choc sur la terre, car puvire signifie frapper (éd. C. L. F. Panckoucke, Paris, 1846).

\section{RÉSUMÉS}

Cet article vise à donner un bref aperçu des principales représentations de la famille des gallinacés dans l'Antiquité gréco-romaine. Par sa beauté et son ardeur au combat, le coq (gallus) domine l'imaginaire et les figurations. Il jouit d'une réputation d'orgueil et de bravoure, qui en fait un symbole de la victoire. Le jeune poulet (pullus) est associé à la vie religieuse et politique sous la République, comme agent dans le rituel de divination du tripudium. Quant à la poule ( gallina), produit d'élevage et de consommation, elle interroge les pratiques agronomiques; les techniques d'engraissement lui ouvrent le marché des denrées de luxe et de la gastronomie.

This paper aims to give a brief overview of the main representations of the Gallinacea family in the Graeco-Roman world. The cock (gallus) by its beauty and its ardor in fighting dominates imagination and is most often pictured; it enjoys a reputation for pride and bravery that allows it 
to be a symbol of victory. The young chicken (pullus) is associated with the religious and political life under the Republic, as acting in the ritual of divination of the tripudium. Being a product of breeding and consumption, the hen (gallina) questions agronomic practices; fattening techniques turn it into an expensive and gastronomic food.

INDEX

Mots-clés : coq (combat de), victoire, divination, poulet sacré, poule, agronomie, xenia, Apicius Keywords : cock fight, victory, divination, sacred chickens, hen, agronomy, xenia, Apicius

\section{AUTEUR}

\section{NICOLE BLANC}

CNRS-ENS, UMR 8546

Directeur de recherche émérite

45 , rue d'Ulm

F - 75230 Paris cedex 05

nicole.blanc@ens.fr 